\title{
Optimization of water quality monitoring network in a large river by combining measurements, a numerical model and matter-element analyses
}

\author{
Qiuwen Chen ${ }^{\mathrm{a}, \mathrm{b}, *}$, Wenqiang $\mathrm{Wu}^{\mathrm{a}}$, Koen Blanckaert ${ }^{\mathrm{a}, \mathrm{c}}$, Jinfeng Ma ${ }^{\mathrm{a}}$, Guoxian Huang ${ }^{\mathrm{a}}$ \\ ${ }^{a}$ Research Centre for Eco-Environmental Sciences, Chinese Academy of Sciences, Beijing, China \\ ${ }^{\mathrm{b}}$ China Three Gorges University, Yichang, China \\ ${ }^{\mathrm{c}}$ Laboratory of Hydraulic Constructions, School of Architecture, Civil and Environment Engineering, École Polytechnique Fédérale Lausanne, Lausanne, Switzerland
}

\section{A R T I C L E I N F O}

\section{Article history:}

Received 12 October 2011

Received in revised form

17 May 2012

Accepted 30 May 2012

Available online

\section{Keywords:}

Water quality

Monitoring station

Optimization

Numerical model

Statistical analysis

\begin{abstract}
A B S T R A C T
A monitoring network that resolves the spatial and temporal variations of the water quality is essential in the sustainable management of water resources and pollution control. Due to cost concerns, it is important to optimize the monitoring locations so to use the least number of stations required to obtain the most comprehensive monitoring. The optimal design of monitoring networks is commonly based on the limited data available from existing measuring stations. The main contribution of this paper is the use of a numerical water quality model, calibrated with the available data. This model yields information on the water quality in any cross-section along the river, including the river reaches that are not monitored. Another contribution of the paper is the use of a matter-element analysis that allows for an objective division of the river in reaches that are homogeneous with respect to the water quality as assessed from multiple water quality parameters. The optimal monitoring network consists of one measuring station in each of these homogeneous reaches. The method has been applied to optimize the water quality monitoring network on the $1890 \mathrm{~km}$ long upper and middle reaches of the Heilongjiang River in Northeast China. The results suggest that the monitoring network improves considerably by relocating three stations, and not by adding extra stations.
\end{abstract}

(c) 2012 Elsevier Ltd. All rights reserved.

\section{Introduction}

Water quality is essential to the health of aquatic ecosystems and human beings (Ward et al., 1990; Wang, 2008). Many countries, in particular developing countries, suffer from quantity-induced and quality-induced water scarcity (Yang and Zehnder, 2007). Proper monitoring can provide important information on the status and spatial-temporal changes of the water quality. Moreover, this can help support water resources, environmental capacity use and pollution control.

The water quality in a large water system is characterized by significant spatial-temporal variations due to differences in background concentrations, pollution sources or hydrological conditions. A comprehensive view of the water quality obtained through an appropriate monitoring network is thus required. Obviously, more monitoring stations yield data of higher quality. However, from a cost point of view, it is essential to use as few stations as

\footnotetext{
* Corresponding author. Research Centre for Eco-Environmental Sciences, Chinese Academy of Sciences, Shuangqing Road 18, Haidian District, Beijing, China. Tel./fax: +861062849326.

E-mail address: qchen@rcees.ac.cn (Q. Chen).
}

possible, optimally located, to measure the water quality and its spatial-temporal variations (Chilundo et al., 2008; Strobl and Robillard, 2008).

In previous studies, empirical, statistical and ranking methods have been applied to design monitoring systems (Lao et al., 1996; Strobl and Robillard, 2008; Telci et al., 2009). The empirical methods enable to design a monitoring scheme according to the available knowledge, the layout of the main stream, the layout of the tributaries and the distribution of the major pollution sources (Chilundo et al., 2008; MacDonald et al., 2009). Statistical methods can identify important measuring stations by assessing the ratio of explained data to the spatial-temporal variations of the water quality in the monitored region (Ouyang, 2005; Strobl et al., 2006a, 2006b; Hunt et al., 2008; Khalil and Ouarda, 2009). Other methods; e.g. matter element analysis (Gao, 1997; Ma and Jiang, 2006; Wu et al., 2010), fuzzy clustering (Liang et al., 2002; Karamouz et al., 2009), genetic algorithms (Icaga, 2005; Park et al., 2006; Telci et al., 2009) and entropy analyses (Mahjouri and Kerachian, 2011) have been applied as well to optimize water quality monitoring networks.

All these methods are based on data collected from an existing monitoring network, that may not be properly located, implying 
that some important information could be missing (Letcher et al., 2002; Strobl et al., 2006b). The ideal approach would consist in conducting high-resolution monitoring campaigns under different hydrological conditions and then identify the representative locations for monitoring stations by analysing the collected data (Bendoricchio and De Boni, 2005). However, this is economically not feasible, especially for large rivers (Letcher et al., 2002; Strobl et al., 2006a, 2006b; Hunt et al., 2008). Lobuglio et al. (2007) proposed a method to assess water quality through the integration of monitoring data and modelling results, but they did not optimize the monitoring networks.

The main contribution of this paper is the inclusion of numerical simulations, using a model for the flow and the water quality, which allow for the extension of the limited dataset, obtained from the existing sub-optimal monitoring network. The extended dataset includes the flow and water quality parameters at any crosssection in the river. Another contribution of the paper is the application of a matter-element analysis to the extended dataset, which allows for an objective determination of the optimal design of the water quality monitoring network that takes into account multiple water quality parameters.

Section 2 presents the case study and the data obtained by means of the existing sub-optimal monitoring network. Section 3 briefly presents the numerical model for the flow and the water quality, its calibration and validation for the investigated case study and its use to extend the experimental database. Section 4 briefly presents the matter-element analysis and illustrates its application to the case study in order to define the optimal network design. Section 5 discusses the results.

\section{Field observations by means of the existing sub-optimal monitoring network}

\subsection{Description of the study area}

A case study on the Heilongjiang River in Northeast China is provided to demonstrate the applicability and potential of the proposed extended methodology. The main stream of the Heilongjiang River is $2865 \mathrm{~km}$ long, and divided into an $894 \mathrm{~km}$ upstream reach, a $996 \mathrm{~km}$ middle reach and a $975 \mathrm{~km}$ downstream reach. Since the downstream reach is entirely in the Russian territory, it is not included in the study. This study focuses on the upstream and middle reaches, which form the boundary between Russia and China. Fig. 1 schematizes the upper and middle reaches and their 41 main tributaries.

In the mountainous upstream reach, the river has a singlethread meandering morphology that is largely in a natural state. The river width is $300-800 \mathrm{~m}$ and the averaged bed slope is about $0.2 \%$. The bed material mainly consists of pebbles and coarse sand. The mean velocity is about $1.5-2.5 \mathrm{~m} \mathrm{~s}^{-1}$ and the channel is icecovered from middle November to the end of April. In the mainly plain middle reach, the river has a compound meandering morphology that is largely in a natural sate, except for navigation maintenance. The river width is $600-1300 \mathrm{~m}$ and the averaged bed slope is about $0.09 \%$. The bed material mainly consists of gravel and medium sand. The sediment concentration is very low and the channel morphology is quite stable. The mean velocity is about $1.0-1.3 \mathrm{~m} \mathrm{~s}^{-1}$ and the channel is ice-covered from middle November to the end of next March. A field investigation in 9 crosssections along the river allowed for determining the variation of the mean diameter $\left(D_{50}\right)$ of the bed substrate (Fig. 2$)$, which decreases gradually from a maximum value of about $53 \mathrm{~mm}$ in the upstream reach to about $0.5 \mathrm{~mm}$ in the downstream reaches.

The selection of water quality parameters is essential to the final result of the network optimization because different parameter sets may lead to different networks. According to the results (unpublished document) of a Chinese-Russian joint monitoring campaign in the period 2007-2011, the main water quality problem is that the chemical oxygen demand $\left(\mathrm{COD}_{\mathrm{Mn}}\right)$ and the ammonia $\left(\mathrm{NH}_{3}-\mathrm{N}\right)$ do not meet the required standards. Therefore, the present monitoring network optimization focuses on these two parameters.

\subsection{Data provided by the existing sub-optimal monitoring network}

The existing sub-optimal water quality monitoring network has been in operation for more than 15 years and consists of 5 stations along the river, indicated by No. 6, 7, 11, 12 and 13 in Fig. 1. Samples are collected and analysed at a monthly interval except for icecovering periods. In order to enhance the spatial resolution of the monitoring network as well as the accuracy of the data extension by means of a numerical model, 8 additional temporary stations (No. 2, 3, 4, 5, 8, 9, 10, 15 in Fig. 1) were sampled 3 times in 2008 under 3 different hydrological conditions that are low flow season (February), even flow season (June) and high flow season (August).

There are 4 hydrological stations in the main stream that are indicated by a, b (overlap with water quality monitoring station No. 6), c (overlap with water quality monitoring station No. 7) and d in Fig. 1. More than 20 years of data has been recorded from these 4 stations, including daily averaged rainfall, water level, discharge, $\mathrm{pH}$, conductivity and water temperature. Meanwhile, water quality parameters such as dissolved oxygen, total suspended substrate, $\mathrm{COD}_{\mathrm{Mn}}, \mathrm{NH}_{3}-\mathrm{N}, \mathrm{NO}_{3}-\mathrm{N}, \mathrm{PO}_{4}-\mathrm{P}$, etc., have been recorded at a monthly interval except for ice-covering period.

Hence, water quality data is available from a total of 15 $(5+8+4-2=15)$ stations in the main stream. All the 41 main tributaries are gauged at the outlet, providing measured daily averaged inflow and monthly water quality parameters. Data from tributaries arriving from the Russian side of the River is provided in the framework of a bilateral exchange agreement between both countries.

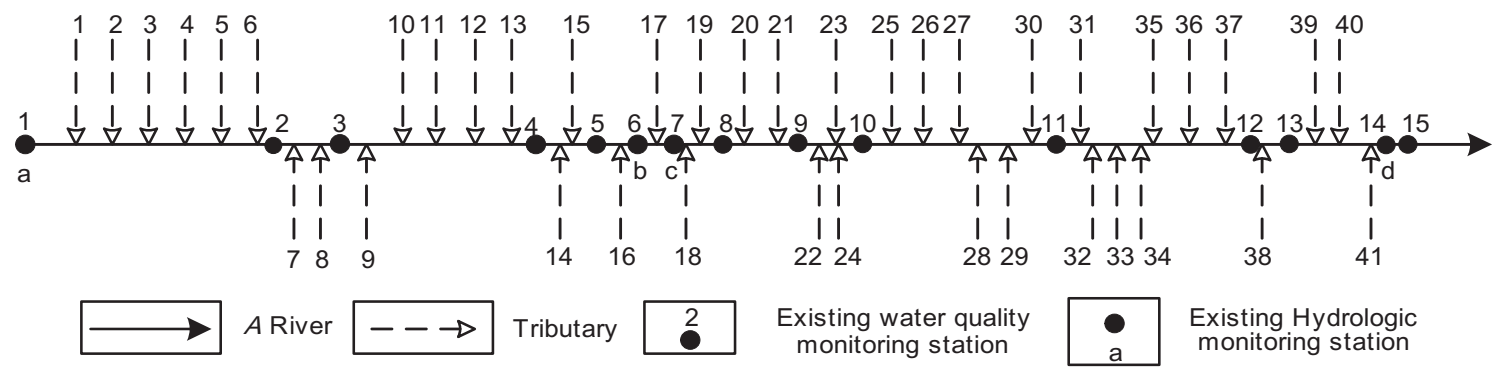

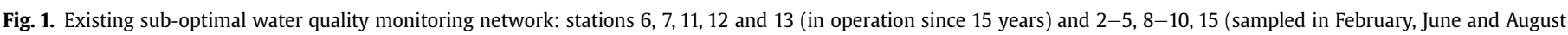
2008). Hydrological monitoring stations $\mathrm{a}-\mathrm{d}$ (in operation since 20 years). 


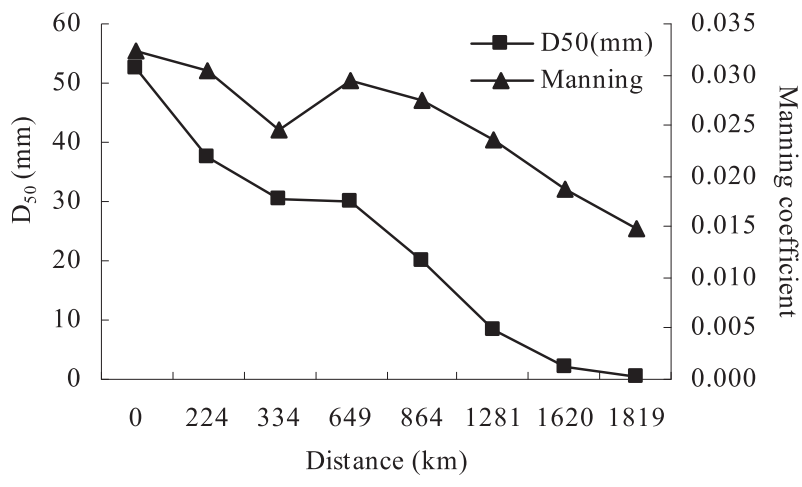

Fig. 2. Longitudinal variations of mean sediment diameter $D_{50}(\mathrm{~mm})$ and Manning coefficient $n\left(\mathrm{~m}^{-1 / 3} \mathrm{~s}^{1}\right)$.

\section{Extension of the monitoring data by means of flow and water quality modelling}

\subsection{The flow and water quality models}

When considering a river length that is orders of magnitude larger than the river width a one-dimensional numerical model is appropriate. Such a model provides flow and water quality variables averaged over each cross-section of the river. This research used the commercial Delft3D software package, including the water quality process library Delwaq (Delft3D-WAQ, 1999). This package implements a numerical solver based on the finite difference method.

The flow is described by the Saint-Venant equations, which express the conservation of mass and momentum, respectively (Abbott and Minns, 1998):

$\frac{\partial A}{\partial t}+\frac{\partial Q}{\partial x}=0$

$\frac{\partial Q}{\partial t}+\frac{\partial}{\partial x}\left(\frac{Q^{2}}{A}\right)+g A \frac{\partial H}{\partial x}+\frac{n^{2} g Q|Q|}{R^{4 / 3} A}=0$

where $t(\mathrm{~s})$ is time, $x(\mathrm{~m})$ is the distance along the channel axis, $A$ $\left(\mathrm{m}^{2}\right)$ is the total flow area of the cross-section, $Q\left(\mathrm{~m}^{3} \mathrm{~s}^{-1}\right)$ is the discharge, $g\left(\mathrm{~m} \mathrm{~s}^{-2}\right)$ is the gravitational acceleration, $H(\mathrm{~m})$ is the water surface elevation, $n\left(\mathrm{~m}^{-1 / 3} \mathrm{~s}^{1}\right)$ is the Manning friction coefficient, $R(\mathrm{~m})$ is the hydraulic radius.

Water quality parameters are modelled by means of the advection-diffusion-reaction equation, including source and sink terms (Ji, 2008).

$\frac{\partial A C}{\partial t}+\frac{\partial Q C}{\partial x}=\frac{\partial}{\partial x}\left(D_{x} \frac{\partial A C}{\partial x}\right)+A S+A f_{R}(C, t)$

$C\left(\mathrm{~g} \mathrm{~m}^{-3}\right)$ is the concentration of the water quality parameter, $D_{x}$ $\left(\mathrm{m}^{2} \mathrm{~s}^{-1}\right)$ is the diffusion coefficient, $S\left(\mathrm{~g} \mathrm{~m}^{-3} \mathrm{~s}^{-1}\right)$ is the source or sink term, $f_{R}(C, t)$ is the reaction term. The reaction terms for the water quality parameters considered in this study $\left(\mathrm{COD}_{\mathrm{Mn}}\right.$ and $\mathrm{NH}_{3}-\mathrm{N}$ ) are modelled as:

$f_{R}\left(C_{\mathrm{COD}}, t\right)=-k_{1} C_{\mathrm{COD}}$

$f_{R}\left(C_{\mathrm{NH}_{3}-\mathrm{N}}, t\right)=k_{2} C_{\text {org }-\mathrm{N}}-k_{3} C_{\mathrm{NH}_{3}-\mathrm{N}}$

where $C_{\mathrm{COD}}\left(\mathrm{g} \mathrm{m}^{-3}\right)$ is the concentration of COD, $k_{1}\left(\mathrm{~d}^{-1}\right)$ is the degradation coefficient of COD. $C\left(\mathrm{~g} \mathrm{~m}^{-3}\right)$ is the concentration of organic nitrogen, $\mathrm{C}_{\mathrm{NH}_{3}-\mathrm{N}}\left(\mathrm{g} \mathrm{m}^{-3}\right)$ is the concentration of ammonia, $k_{2}\left(\mathrm{~d}^{-1}\right)$ is the degradation coefficient of organic nitrogen, $k_{3}\left(\mathrm{~d}^{-1}\right)$ is the nitrification coefficient.
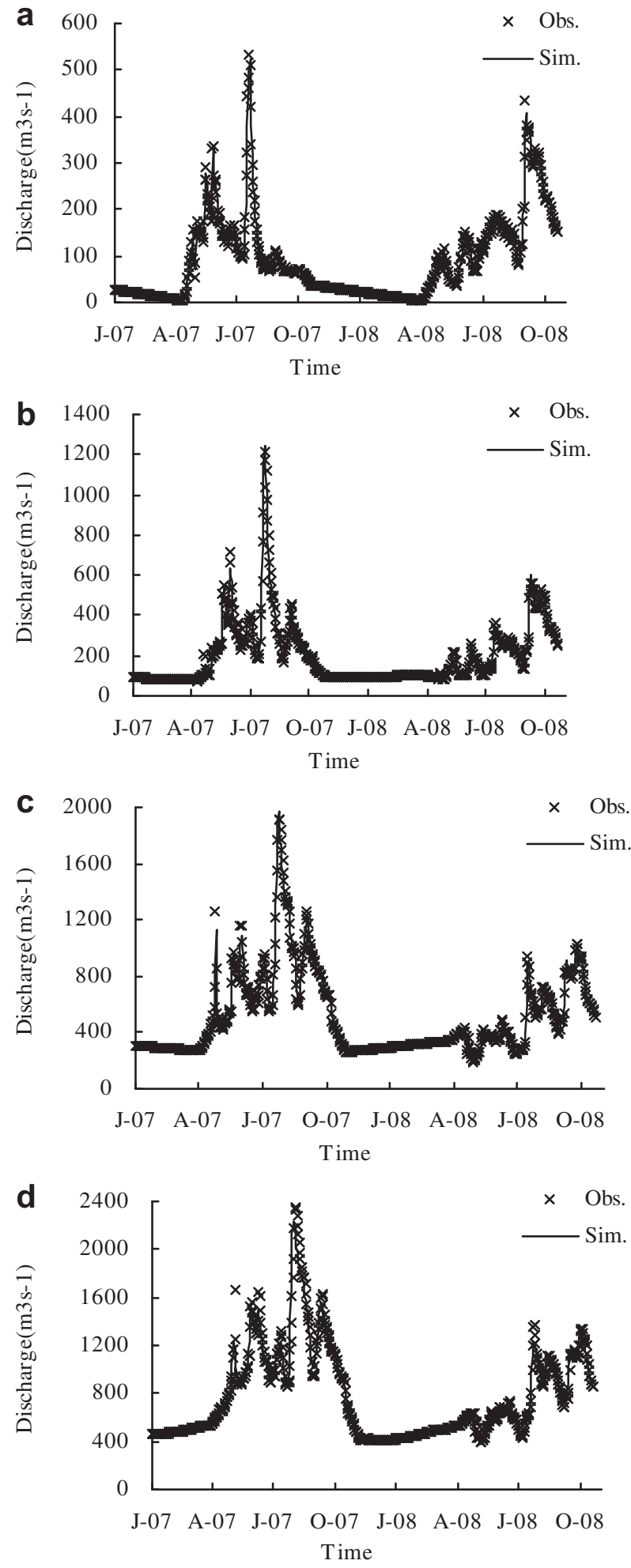

Fig. 3. Comparison of simulated and measured discharges in hydrological stations a-d (Fig. 1) from January 1, 2007 to October 30, 2008

The $1890 \mathrm{~km}$ long reach of the Heilongjiang River has been modelled using this one-dimensional flow and water quality model. The bathymetry of the river bed was obtained from the 'Navigation Chart of Heilongjiang River' (2006), and then 361 crosssections were described in detail. These cross-sections were roughly equidistant in longitudinal direction. Linear interpolation 
was used to generate a computational grid with a spatial step of $\Delta x=1 \mathrm{~km}$, which yields 1891 computational nodes. The optimal time step $(\Delta t)$ of the model was set to be 15 min based on trial and error. At the upstream inflow boundary, measured discharges and water quality parameters provided by the existing monitoring station $a$ (Fig. 1) were imposed. Since all the 41 main tributaries are gauged at the outlet, measured inflow and water quality parameters were provided at the tributary nodes. At the downstream boundary, a rating curve was imposed that relates the discharge to the water surface elevation.

\subsection{Model calibration and validation}

In this study, the data provided by the existing sub-optimal monitoring network for the flow and water quality was used to calibrate and validate the numerical model for the flow and water quality. Data from the years 2005 and 2006 was used to calibrate the model. The optimal choice of the calibration coefficients was obtained with the 'GLOBE' tool (Solomatine, 1998, 1999) for global optimization of multiple parameters, and the root mean square error between observations and model outputs was the criterion. This calibration does not guarantee, however, that the model captures satisfactorily the dominant processes and can be used as a reliable tool to extend the dataset. Therefore, the calibrated model was validated by means of comparison of model predictions to measured data that is independent of that used for the model calibration.

Calibration of the flow model consisted in optimally defining the Manning friction coefficient $n$ (Equation (2)). The initial values of $n$ were estimated according to the grain size of the 9 typical sections indicated in Fig. 2 based on Julien (2002)'s formula, $n=0.062 D_{50}^{1 / 6}$, where $D_{50}$ is the mean grain size expressed in (m). Subsequently 'GLOBE' was used to obtain the optimal values. The daily averaged water levels and discharges measured by the 4 existing hydrological stations $\mathrm{a}-\mathrm{d}$ (Fig. 1) were used for the calibration and validation of the flow model. Because the cross-sections were defined from the 'Navigation Chart of Heilongjiang River' (2006), which was based on a survey in 2005 , only the data after 2005 were used in the study. The measurements in the period from January 1, 2005 to December 31, 2006 were used for the model calibration, whereas the measurements from January 1, 2007 to October 30, 2008 were used for the validation. Fig. 3 presents the comparisons between observed and modelled discharges for the validation dataset. The relative errors for all the four hydrological stations $(\mathrm{a}-\mathrm{d})$ are within $0.3 \%$.

Calibration of the water quality model consisted in optimally defining the diffusion coefficient $D_{x}$ (Equation (3)) and the
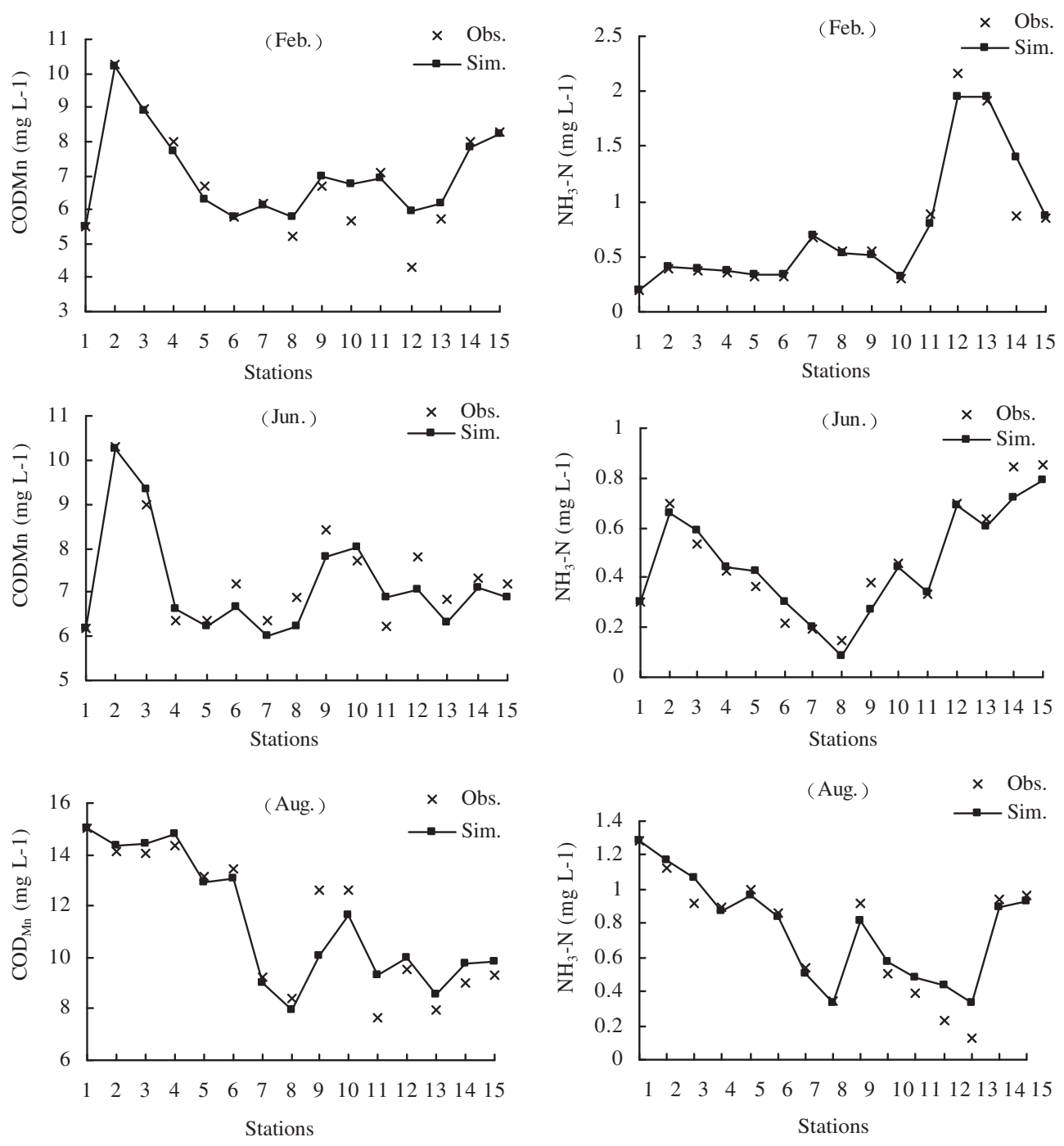

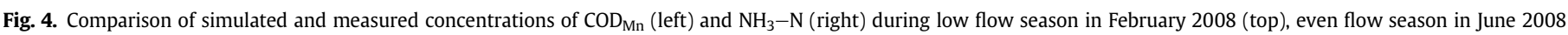
(middle) and high flow season in August 2008 (bottom). 
reaction coefficients $k_{1}, k_{2}$ and $k_{3}$ (Equations (4) and (5)). The initial values were estimated according to the literature (Chen et al., 2009), and then 'GLOBE' was used to obtain the optimal values. The water quality model was calibrated by means of the monthly observations of the 5 existing water quality monitoring stations (Fig. 1) in the period from January 2005 to December 2006. The validation of the model was subsequently performed by comparing model predictions to data measured by all 15 water quality monitoring stations (Fig. 1) during three typical hydrological seasons of interest in 2008, corresponding to low flow (February), even flow (June) and high flow (August). Fig. 4 compares the measured and simulated concentrations of $\mathrm{COD}_{\mathrm{Mn}}$ and $\mathrm{NH}_{3}-\mathrm{N}$ in all 15 monitoring stations along the river. The relative errors are within $2.72 \%$ for $\mathrm{COD}_{\mathrm{Mn}}$ and are within $8.50 \%$ for $\mathrm{NH}_{3}-\mathrm{N}$. The final coefficients after calibration are summarized in Table 1.

The calibrated and validated water quality model provides COD and $\mathrm{NH}_{3}-\mathrm{N}$ concentrations at any cross-section along the main stream. Three scenarios are simulated, corresponding to the three typical hydrological seasons.

\section{Optimal design of the water quality monitoring network by means of matter-element analysis}

\subsection{Matter-element analysis}

The idea of the adopted method is to identify river reaches with homogeneous water quality characteristics that can efficiently be monitored by means of one measuring station. This means that measuring stations can be eliminated in homogeneous reaches that are at present equipped by multiple measuring stations, and that new measuring stations need to be installed in homogeneous reaches that are at present unequipped. The definition of reach of homogeneous water quality is not absolute and depends on the methodology used. The adopted methodology will therefore first be outlined, and the meaning of a reach with homogeneous water quality will subsequently be clarified.

River reaches that are homogeneous with respect to their water quality are identified by means a Matter-Element Analysis (MEA), also called extenics theory. Wu et al. (2010) applied MEA to optimize river monitoring networks, and compared it with other statistical methods including fuzzy logic and grey clustering, while the combination with numerical modelling was only briefly mentioned. Reference is made to Cai $(1983,1999)$, Wang (2001) and Cai et al. (2003) for a detailed description of MEA, while only the essential elements required to make the present paper selfcontained are reported hereafter.

For each cross-section of the river where experimental or numerical data is available, the water quality parameters are represented as:

$K_{a}\left(X_{j}^{i}\right)=\frac{X_{j}^{i}-c_{j}}{c_{j}-a_{j}}$

Table 1

Calibrated parameters of flow and water quality models.

\begin{tabular}{llll}
\hline Parameters & Symbol & Unit & Value \\
\hline Manning coefficient & $n$ & $\mathrm{~m}^{-1 / 3} \mathrm{~s}^{1}$ & $0.015-0.032$ (see Fig. 2) \\
Diffusion coefficient & $D_{x}$ & $\mathrm{~m}^{2} \mathrm{~s}^{-1}$ & 0.01 \\
COD degradation coefficient & $k_{1}$ & $\mathrm{~d}^{-1}$ & 0.12 \\
$\begin{array}{c}\text { Organics nitrogen } \\
\quad \text { degradation coefficient }\end{array}$ & $k_{2}$ & $\mathrm{~d}^{-1}$ & 0.09 \\
Nitrification coefficient & $k_{3}$ & $\mathrm{~d}^{-1}$ & 0.11 \\
\hline
\end{tabular}

$K_{b}\left(X_{j}^{i}\right)=\frac{X_{j}^{i}-c_{j}}{c_{j}-b_{j}}$

where the index $i$ and $j$ represent the cross-section and water quality parameter considered, respectively, and $a, b, c$ represent the lowest, highest and average value, respectively, of the considered water quality parameter over the entire river reach (Fig. 4). $K_{a}$ and $K_{b}$ can therefore be interpreted as the normalized deviations of the water quality parameters from their average values.

Obviously, the parameters $K_{a}$ and $K_{b}$ are equivalent when only one water quality parameter is considered. This is not the case anymore, when composite values of $K_{a}$ and $K_{b}$ are considered that take into account multiple water quality parameters according to:

$$
\begin{aligned}
& K_{a}\left(X^{i}\right)=\sum_{j=1}^{n} W_{j} K_{a}\left(X_{j}^{i}\right) \\
& K_{b}\left(X^{i}\right)=\sum_{j=1}^{n} W_{j} K_{b}\left(X_{j}^{i}\right)
\end{aligned}
$$

The weight $W_{j}$ is given by

$$
\begin{aligned}
& W_{j}=\frac{P_{j}}{\sum_{j}^{n} P_{j}} \\
& P_{j}=\frac{\frac{1}{2}\left(a_{j}+b_{j}\right)}{\frac{1}{5} \sum_{k=1}^{5} S_{j k}}
\end{aligned}
$$

The numerator $1 / 2\left(a_{j}+b_{j}\right)$ in Equation (11) represents the average of the lowest and highest values of the concerned water quality parameter $j$ in the investigated river. The parameter $S_{j k}$ in the denominator represents the threshold value of class $k$ for water quality parameter $j$ in the national water quality standard (GB38382002), which has five classes $\left(k_{\max }=5\right)$. According to Equation (11), the higher the pollution for the water quality parameter $j$, the higher its corresponding weight factor $P_{j}$. Equation (10) normalizes the weight factors for the different water quality parameters, such that their sum is equal to 1 .

A chart of $K_{a}$ vs. $K_{b}$ (Fig. 5) provides an alternative representation of the spatial distribution and heterogeneity of the water quality along the river. The centre of the plot, $\left(K_{a}, K_{b}\right)=(0,0)$, represents the average value of the water quality in the river. Cross-sections with low (high) values of the water quality parameters are situated in the lower-right (upper-left) corner of the chart. The deviation of the data points from a single line represents differences in the spatial distribution of both water quality parameters considered. A cluster of points represents cross-sections with a very similar water quality.

The $K_{a}-K_{b}$ graph allows for an objective assessment and improvement of monitoring networks. The ideal monitoring network would be characterized by identical differences in water quality between neighbouring monitoring stations, which would correspond to identical Euclidian distances between points corresponding to neighbouring monitoring stations in the $K_{a}-K_{b}$ chart. Such an ideal monitoring network would divide the river in reaches of homogeneous water quality. It should be noted that this definition of reach of homogeneous water quality is not absolute, but accounts implicitly for the different water quality parameters and the number of measuring stations. An over-sampled (undersampled) river reach is represented by neighbouring monitoring stations that are represented in the $K_{a}-K_{b}$ chart by point that are 

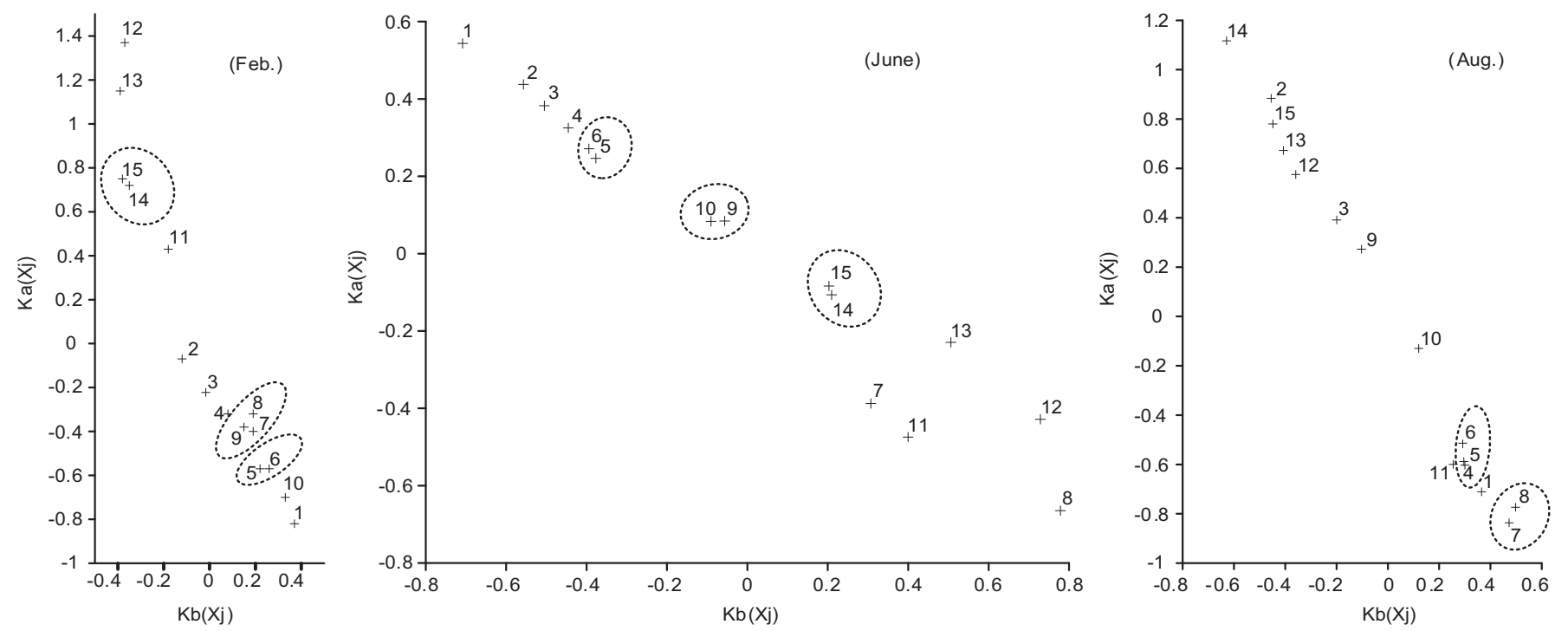

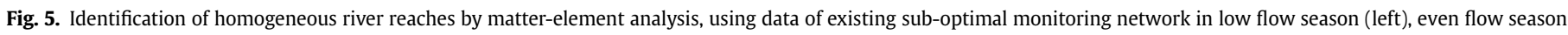
(middle) and high flow season (right). $K_{a}$ and $K_{b}$ are defined according to Equations (8) and (9).

separated by less (more) than the average distance between the points.

\subsection{Monitoring network optimization}

The matter-element analysis is first applied to the 15 stations of the existing sub-optimal water-quality monitoring network. Results for the low, even and high flow seasons are visualized in Fig. 5. The stations in each dash-lined circle are situated within the same homogeneous river reach, and can be merged.

Obviously, application of the matter-element analysis on the 15 stations of the existing sub-optimal water-quality monitoring network does only allow for the identification of redundant measuring stations in reaches with homogeneous water quality. It does not allow, however, for the identification of the optimal number of measuring stations and their location, which requires application of the matter-element analysis on data in a number of cross-sections that is significantly larger than the number of monitoring stations.

For that purpose, the matter-element analysis is subsequently applied on simulated data provided by the water quality model in 94 cross-sections. These cross-section have been selected as follows: $82\left(41^{*} 2\right)$ cross-sections are located just upstream and downstream of the 41 tributary inflows, 10 cross-sections $\left(5^{*} 2\right)$ are located just upstream and downstream of the 5 major cities (Huma, Hehei, Xunke, Jiayin and Fuyuan), 1 cross-section is located at the upstream boundary and 1 cross-section is located at the downstream boundary. Results for the low, even and high flow seasons are visualized in Fig. 6, which identifies the stations that are situated within the same homogeneous river reach and can be merged.

Fig. 7 situates the 15 stations of the existing sub-optimal water quality monitoring network with respect to the 94 cross-sections
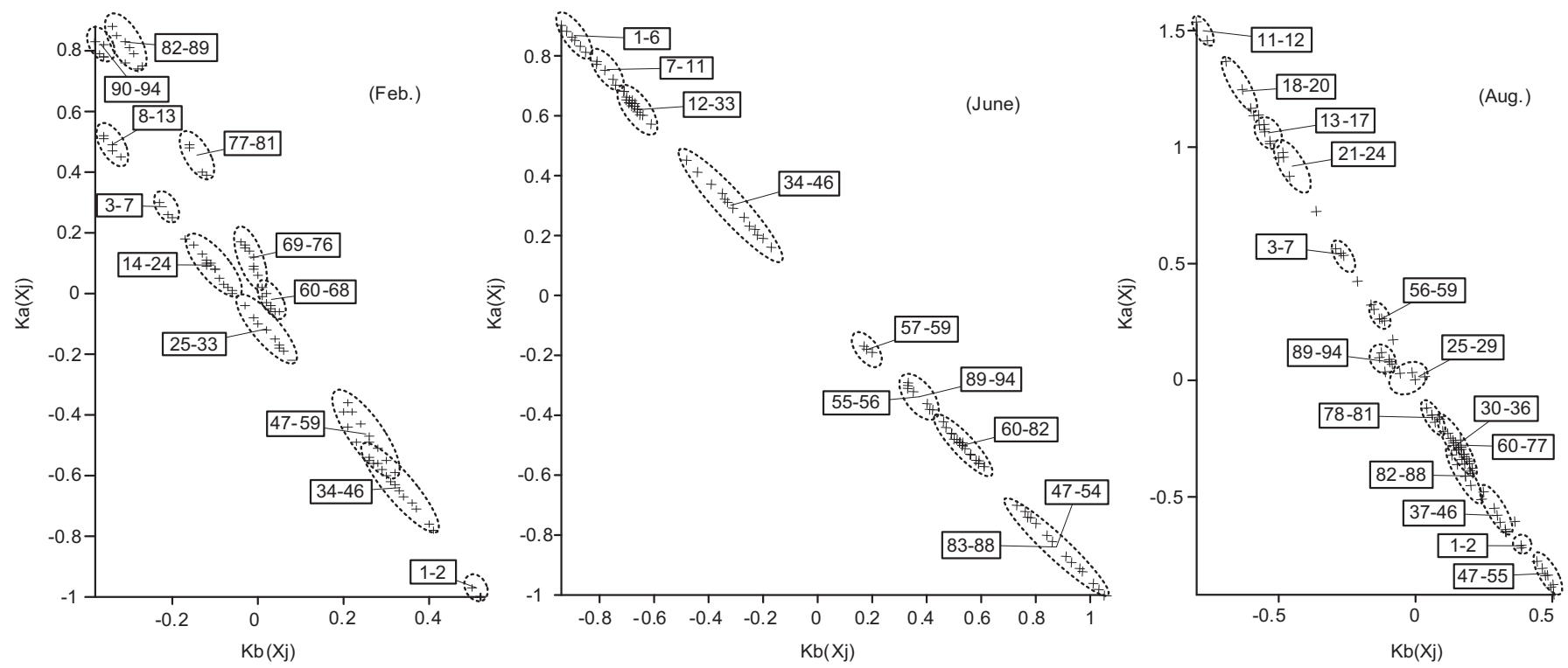

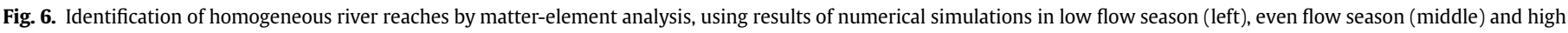
flow season (right). $K_{a}$ and $K_{b}$ are defined according to Equations (8) and (9). 


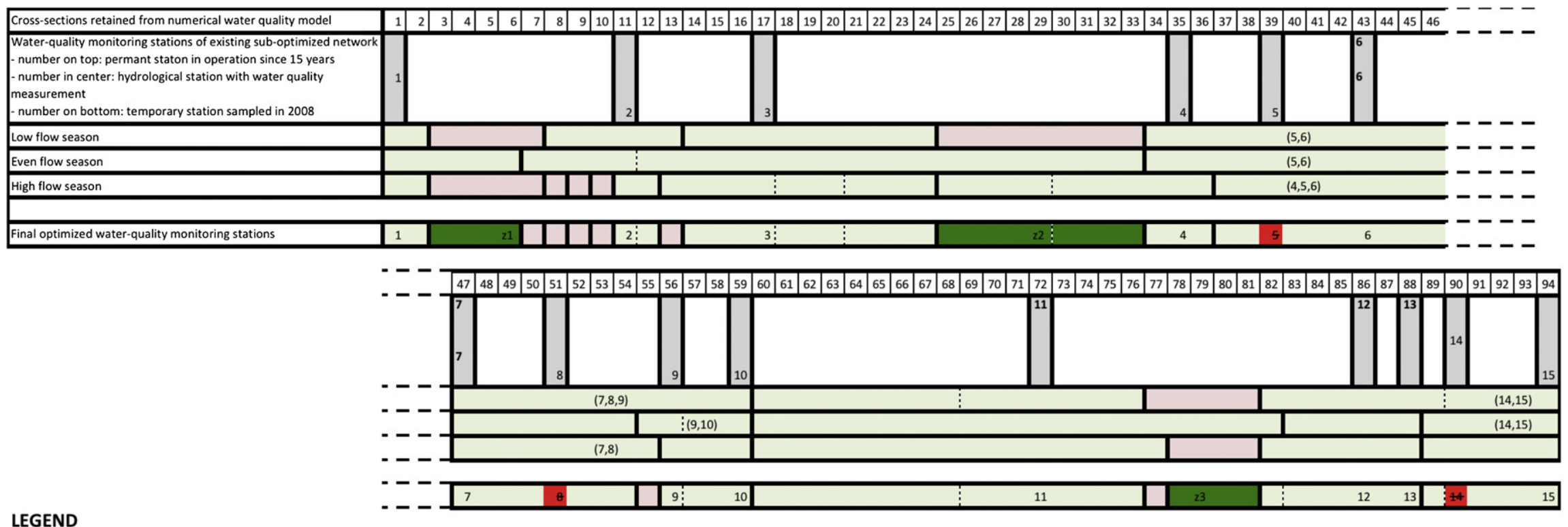

\section{LEGEND}

River reach with homogeneous water quality characteristics, according to

matter-element analysis applied to the 94 retained cross-sections of the numerical model

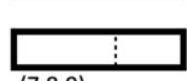

$(7,8,9)$

Dashed line separates two adjacent homogeneous river reaches with very similar water quality

Stations within the same river reach with rather homogeneous water quality characteristics

according to matter-element analysis applied to the 15 non-optimized existing stations

Eliminated station of the sub-optimal existing water-quality monitoring network

\begin{tabular}{|l}
\hline River reach measured by existing water-quality monitoring stations \\
\hline
\end{tabular}

River reach not measured by existing water-quality monitoring stations

$21 \quad$ New station of the optimized water-quality monitoring network

Fig. 7. Schematization of results, indicating: (i) 15 stations of existing sub-optimal monitoring network; (ii) 94 cross-section selected from numerical model; (iii) results of matter-element analysis applied to data from existing stations

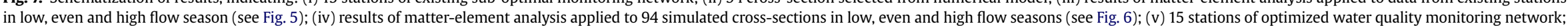
(vi) legend. 


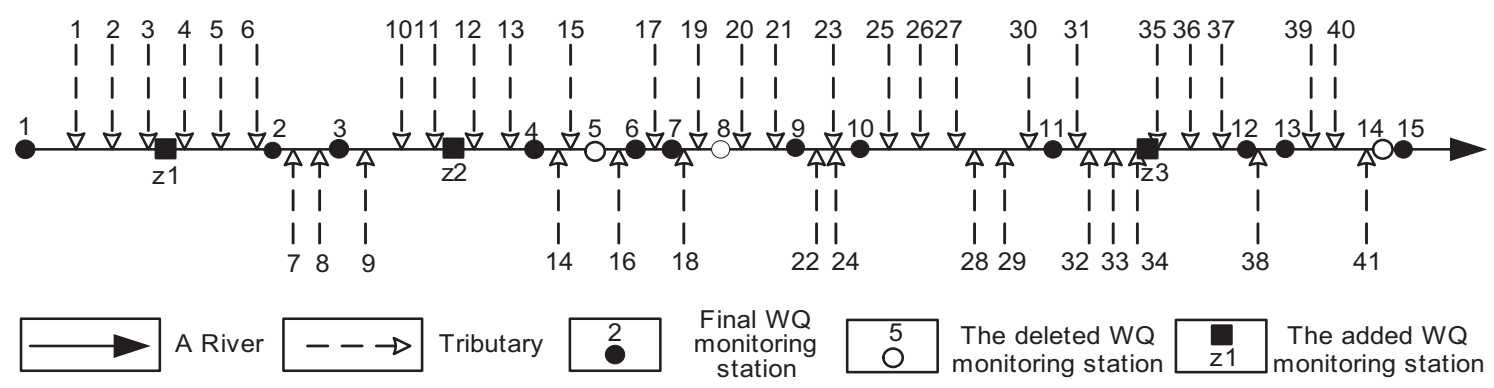

Fig. 8. Optimized water quality monitoring network. To be compared to existing sub-optimal network (Fig. 1).

retained from the numerical model, and recapitalizes the results of the matter-element analysis. Fig. 7 also allows for defining the optimized water-quality monitoring network based on the following guidelines: (i) stations are preferably situated in river reaches that are characterized by a homogeneous water quality in all flow seasons, (ii) these homogeneous river reaches are preferably long and distributed along the entire length of the river, (iii) for economical reasons, it is preferable to retain a maximum of existing stations and to add a minimum of new stations.

These guidelines lead to the following definition of the optimized water-quality monitoring network (Fig. 7):

- The matter-element analysis indicates three homogeneous river reaches that are at present equipped with two measuring stations. It is decided to retain the permanent stations 6 and 7 in favour of the temporary stations 5 and 8 , which will be eliminated. The temporary station 15 will be retained because it is the most downstream station, and station 14 in the same homogeneous river reach will be eliminated.

- The matter-element analysis indicates three rather long homogeneous river reaches that are at present not monitored. New water-quality monitoring stations z1, z2 and z3 (Fig. 7) will be installed in these reaches. Taking into account the accessibility and straight watercourse, the cross-sections of 6 , 29 and 79 are suggested for installing these new monitoring stations.

\section{Discussion}

The optimized water quality monitoring network consists of the 15 stations indicated in Figs. 7 and 8. The latter Figure allows straightforward comparison to the existing sub-optimal waterquality monitoring network shown in Fig. 1. Obviously, a monitoring network can never provide complete information on the water quality all along the river. But the 15 stations provide a rather complete view and only few locations along the river will not be optimally monitored, as indicated in Fig. 7.

The flow dynamics differ in the low, even and high flow seasons. It could therefore be expected that the homogeneous river reaches identified by the matter-element analysis are not identical for the three flow seasons. The matter-element analysis does identify, however, rather long river reaches that are characterized by homogeneous water quality conditions in all three flow seasons. These reaches are distributed along the entire investigated length of the river.

The matter-element analysis on the 15 stations of the existing sub-optimal monitoring network and on the 94 cross-sections retained from the numerical model are largely in agreement, although some differences exist. As an example, existing stations 7 and 8 are within the same homogeneous reach in all flow seasons according to the result of the numerical model, whereas they are only in the same homogeneous reach during low and high flow season according to the analysis of the measured water-quality data (Fig. 7). These differences are not surprising, since a onedimensional numerical model cannot be expected to resolve all details of the distribution of the water quality model in a natural river with a complex geometry.

The results do clearly show the added value of the numerical simulations: they do confirm the result of the matter-element analysis based on the existing sub-optimal monitoring stations, and they allow identifying homogeneous river reaches that are not covered by the existing stations. Comparing to the methods in previous studies, the proposed approach that combined numerical simulations has obvious advantage to provide more completed information at low cost when optimizing the monitoring network. However, the performance and reliability of the numerical model depend very much on the quality of the observations available from the existing monitoring network. Therefore, the network optimization through this combined method is an iterative process.

The optimized monitoring network is based on information including river network structure, hydrological regime and key water quality parameters. Significant modifications to the river system, such as dam construction or removal, appearance or disappearance of large industrial plants, would require the extension of the optimized monitoring network with additional stations. An entire re-optimization of the monitoring network is only required in case of a change in the dominant parameters of relevance with respect to the water quality.

\section{Conclusions}

This paper proposed and illustrated a method for the optimal design of a water quality monitoring network on a large river system, which has two key advantages and originalities. First, it uses the limited available data from an existing sub-optimal water quality monitoring network to calibrate and validate a numerical model. This model is subsequently applied to extend the dataset and to provide information on river reaches that are not experimentally monitored. Second, it uses a matter-element analysis on the experimental and numerically extended datasets in order to divide the entire length of the river into homogeneous reaches with respect to the water quality. This method allows for an objective definition of homogeneous reaches that takes into account multiple water quality parameters. Optimally, one monitoring stations should be installed in each of the homogeneous river reaches.

The method was applied to optimize the water quality monitoring network on the $1890 \mathrm{~km}$ long upper and middle reaches of the Heilongjiang River in Northeast China, which consists of 15 existing measuring stations. On this river, the chemical oxygen demand $\left(\mathrm{COD}_{\mathrm{Mn}}\right)$ and the ammonia $\left(\mathrm{NH}_{3}-\mathrm{N}\right)$ were identified as the two most relevant parameters with respect to the water quality. The results indicate that at present three homogeneous river 
reaches are equipped with two monitoring stations, whereas three long homogeneous reaches are not monitored. A considerable improvement of the water quality network can therefore be obtained by displacing three of the redundant stations to the homogeneous reaches that are not monitored at present.

\section{Acknowledgements}

This study was partially supported by the National Fundamental Research Program (No. 2010CB429004), National Nature Science Foundation of China (50920105907), "100 Talent Program of Chinese Academy of Sciences (A1049)", Chinese Academy of Science (KZCX1-YW-06) and the Chutian Scholarship (KJ2010B002). Blanckaert was partially funded by the Chinese Academy of Sciences Visiting Professorship for Senior International Scientists, grant number 2011T2Z24, and by the Sino-Swiss Science and Technology Cooperation for the Institutional Partnership Project, grant number IP13_092911.

\section{References}

Abbott, M.B., Minns, A.W., 1998. Computational Hydraulics, second ed. Ashgate Publishing Company, London.

Bendoricchio, G., De Boni, G., 2005. A water-quality model for the Lagoon of Venice, Italy. Ecological Modelling 184, 69-81.

Cai, W., 1983. Extension Set and Exclusive Problems. Sciences Exploration (in Chinese).

Cai, W., 1999. Extension theory and its applications. Chinese Science Bulletin 44 (17), 1538-1547

Cai, W., Yang, C., Lin, W., 2003. Extension Engineering Methods. Science Press, Beijing.

Chen, Q., Tan, K., Zhu, C., Li, R., 2009. Development and application of a twodimensional water quality model for the Daqinghe River Mouth of the Dianchi Lake. Journal of Environmental Sciences 21, 313-318.

Chilundo, M., Kelderman, P., O'keeffe, J., 2008. Design of a water quality monitoring network for the Limpopo river Basin in Mozambique. Physics and Chemistry of the Earth, Parts A/B/C 33 (8-13), 655-665.

Delft3D-WAQ 1999. Technical Reference Manual for Delft3D-WAQ WL | Delft Hydraulics, Version 3.01.

Gao, M., 1997. Study on optimized points selection of water quality environmental monitoring by matter element analyses. Advances in Environmental Science 5 (3), 77-81 (in Chinese with English abstract).

Hunt, C., Rust, S., Sinnott, L., 2008. Application of statistical modeling to optimize a coastal water quality monitoring program. Environmental Monitoring and Assessment 137 (1), 505-522.

Icaga, Y., 2005. Genetic algorithm usage in water quality monitoring networks optimization in Gediz (Turkey) river Basin. Environmental Monitoring and Assessment 108 (1), 261-277.

Ji, Z., 2008. Hydrodynamics and Water Quality, Modelling Rivers, Lakes and Estuaries. John Wiley \& Sons, Honoken, New Jersey.

Julien, P.Y., 2002. River Mechanics. Cambridge University Press, UK.

Karamouz, M., Kerachian, R., Akhbari, M., Maksimovic, Č., 2009. Design of river water quality monitoring networks: a case study. Environmental Modeling and Assessment 14 (6), 705-714.
Khalil, B., Ouarda, T.B.M., 2009. Statistical approaches used to assess and redesign surface water-quality-monitoring networks. Journal of Environmental Monitoring 11 (11), 1915-1929.

Lao, S.L., Kuo, J.T., Wang, S.M., 1996. Water quality monitoring network design of Keelung River, Northern Taiwan. Water Science and Technology 34 (12), 49-57.

Letcher, R.A., Jakeman, A.J., Calfas, M., Linforth, S., Baginska, B., Lawrence, I., 2002 A comparison of catchment water quality models and direct estimation techniques. Environmental Modelling \& Software 17 (1), 77-85.

Liang, W.Q., Ye, J.R., Yang, J., 2002. Fuzzy cluster analysis and optimize the urban creek water quality monitoring points. The Administration and Technique of Environmental Monitoring 14 (3), 6-7.

Lobuglio, J.N., Characklis, G.W., Serre, M.L., 2007. Cost-effective water quality assessment through the integration of monitoring data and modeling results. Water Resources Research 43,1-16.

Ma, F., Jiang, L., 2006. River water quality monitoring sections optimal settings research. Environmental Science and Management 31 (8), 171-172.

MacDonald, D.D., Clark, M.J.R., Whitfield, P.H., Wong, M.P., 2009. Designing monitoring programs for water quality based on experience in Canada I. Theory and framework. TrAC Trends in Analytical Chemistry 28 (2), 204-213.

Mahjouri, N., Kerachian, R., 2011. Revising river water quality monitoring networks using discrete entropy theory: the Jajrood river experience. Environmental Monitoring and Assessment 175, 291-302.

Navigation Chart of Heilongjiang River, 2006. Star Map Press, Beijing.

Ouyang, Y., 2005. Evaluation of river water quality monitoring stations by principal component analysis. Water Research 39, 2621-2635.

Park, S.-Y., Choi, J.H., Wang, S., Park, S.S., 2006. Design of a water quality monitoring network in a large river system using the genetic algorithm. Ecological Modelling 199 (3), 289-297.

Solomatine, D.P., 1998. Genetic and other global optimization algorithms comparison and use in model calibration. In: Proceedings of International Conference on Hydroinformatics-98. Balkema, Rotterdam, pp. 1959-1966.

Solomatine, D.P., 1999. Two strategies of adaptive cluster covering with descent and their comparison to other algorithms. Journal of Global Optimization 14 (1) 55-78.

Strobl, R.O., Robillard, P.D., 2008. Network design for water quality monitoring of surface freshwaters: a review. Journal of Environmental Management 87 (4), 639-664.

Strobl, R., Robillard, P., Day, R., Shannon, R., McDonnell, A., 2006a. A water quality monitoring network design methodology for the selection of critical sampling points: part II. Environmental Monitoring and Assessment 122 (1), 319-334.

Strobl, R., Robillard, P., Shannon, R., Day, R., McDonnell, A., 2006b. A water quality monitoring network design methodology for the selection of critical sampling points: part I. Environmental Monitoring and Assessment 112 (1), 137-158.

Telci, I.T., Nam, K., Guan, J., Aral, M.M., 2009. Optimal water quality monitoring network design for river systems. Journal of Environmental Management 90 (10), 2987-2998.

Wang, J., 2001. Extension set theory, extension engineering method and extension system control. Academic Open Internet Journal 5. http://www.acadjournal. com/2001/v5/part5/p1/.

Wang, Z., 2008. Safety Assessment on Drinking Water Quality. Chemical Industry Press, Beijing.

Ward, R.C., Loftis, J.C., McBride, G.B., 1990. Design of Water Quality Monitoring System. John Wiley \& Sons Inc., New York.

Wu, W., Chen, Q., Li, J., Chen, G., 2010. Optimization of river water quality monitoring sections. Acta Scientiae Circumstantiae 30 (8), 1537-1542 (in Chinese).

Yang, H., Zehnder, A., 2007. "Virtual water": an unfolding concept in integrated water resources management. Water Resources Research 43, W12301. http:// dx.doi.org/10.1029/2007WR006048. 